\title{
STRESS AND PROGRESSIVE FAILURE ANALYSIS OF A LAMINATED COMPOSITE ANNULAR DISC
}

\author{
Harish.B ${ }^{1}$, G.S.Mahesh ${ }^{2}$, Thejeswini $\mathbf{M}^{3}$ \\ ${ }^{1}$ M.Tech in design engineering student, Dayananda Sagar College of Engineering, Bangalore, India \\ ${ }^{2}$ Associate Professor, Department of mechanical engineering, Dayananda Sagar College of Engineering, Bangalore, \\ India \\ ${ }^{3}$ Assistant professor, Department of mechanical engineering, Dayananda Sagar College of Engineering, Bangalore, \\ India
}

\begin{abstract}
Composite materials consisting of stiff and strong fibers (glass, carbon, Kevlar, etc) reinforcing a compatible matrix (polymers, metals, ceramics, carbon, etc) in the form of a laminate are engineered materials. This paper presents the results of an investigation into stress analysis and progressive failure analysis (first ply failure to last ply failure) of a laminated composite annular disc made up of glass epoxy and graphite epoxy subjected to spinning. The ANSYS software and its powerful analysis, pre and post-processing capability is exploited to graphically present contour plots of ply by ply stresses in the material co-ordinates and Tsai-Wu failure index.
\end{abstract}

\section{INTRODUCTION}

The structural elements (panel, plate, shell) of composite materials are normally fabricated by lamination process, in which a number of laminae are oriented in a pre-determined manner. For the analysis purpose the lamina is modeled as a homogeneous, orthotropic, elastic continuum characterized by the experimentally measured effective moduli namely longitudinal modulus of elasticity along the fiber direction E1, transverse modulus of elasticity E2, in-plane shear modulus G12 and major poisson's ratio v12. The lamination theories provide a methodology to calculate stretching, bending, stretching-bending coupling stiffness matrices of a multi layered, multi directional composite laminate. The finite element method in general and general purpose finite element analysis software in particular implemented on a digital computer offers a universal procedure for the analysis of composite structures. This paper demonstrates convincingly the application of FEM in general and ANSYS software in particular for stress analysis and progressive failure analysis (first ply failure to last ply failure) of selected composite structures.

Lakshminarayana $^{[1]}$ has presented a paper on finite element analysis of rotating laminated composite annular discs where in the study clearly shows that the stress distribution in a rotating laminated composite annular disc is much more complex than that of a homogeneous isotropic disc. It also shows that the composite material properties and lamination patterns have a remarkable influence on the stress distribution.

The study on unidirectional and cross-ply laminates shows that it creates localized regions where larger stresses and very steep stress gradients (compared with the homogeneous isotropic case) are present. In addition, the deformed shape of the disc is also found to be no longer circular. Nevertheless, the behaviour of a composite disc with a quasi-isotropic lay-up is found to be similar to that of a homogeneous isotropic disc. Belingardi, G. ${ }^{[2]}$, Gent\& G. and Gola, M. have presented a study on the stress distribution in rotating orthotropic disc Composites. Genta, G. ${ }^{[3]}$ and Gola, NL have investigated on the stress distribution in orthotropic rotating disks. Kim and $\mathrm{Hong}^{[4]}$ have presented a progressive failure model for laminated composites based on Finite Element stress Analysis. Chapelle and Bathe ${ }^{[5]}$ presented fundamental considerations for the finite element analysis of shell structures where bending dominated and membrane dominated cases are highlighted.

This paper presents significant results of stress analysis (layer-wise stresses) and progressive failure (first ply failure to last ply failure) analysis of A laminated composite annular disc made up of glass epoxy and graphite epoxy subjected to spinning.

Accurate stress analysis to predict ply by ply stresses in the material co-ordinates is a prerequisite for progressive failure analysis. A verified lamina failure criteria along with experimentally measured stiffness and strength properties of material systems involved is also essential.

\section{FINITE ELEMENT MODELLING}

A Laminated composite annular disc made up of glass epoxy subjected to spinning.

Annular disc made up of unidirectional single ply, cross ply and quasi isotropic ply is considered for the study.

The test specimen shown in fig 1 is a glass-epoxy composite annular disc having a 2:1 annular radius. The physical 
parameters defining the problem are $\mathrm{r}_{\mathrm{i}}=0.01 \mathrm{~m}, \mathrm{r}_{0}=0.1 \mathrm{~m}$ and $\mathrm{t}=0.001 \mathrm{~m}$. The properties of glass epoxy composite lamina used in the analysis are $\mathrm{E}_{1}=38.6 \mathrm{GPa}, \mathrm{E}_{2}=8.27 \mathrm{GPa}$, $\mathrm{G}_{12}=4.14 \mathrm{GPa}, v_{12}=0.26, \rho=2500 \mathrm{~kg} / \mathrm{m} 3, \quad\left(\sigma_{1}{ }^{\mathrm{T}}\right)_{\mathrm{ult}}=1062 \mathrm{MPa}$, $\left(\sigma_{1}{ }^{\mathrm{C}}\right)_{\mathrm{ult}}=610 \mathrm{MPa}, \quad\left(\sigma_{2}^{\mathrm{T}}\right)_{\mathrm{ult}}=31 \mathrm{MPa}, \quad\left(\sigma_{2}{ }^{\mathrm{C}}\right)_{\mathrm{ult}}=118 \mathrm{MPa}$, $\left(\tau_{12}\right)_{\mathrm{ult}}=72 \mathrm{MPa}$.

The finite element model shown in fig 2 was developed using SHELL281 element in ANSYS software. SHELL281 is an iso-parametric layered shell element, quadrilateral in shape, quadratic in order with eight nodes and six engineering degrees of freedom at each node. The graded mesh consists of 400 elements and 1281 nodes.

For the present case, the laminated composite annular disc made up of three different stacking sequence is considered i.e with

i) A single layer unidirectional ply with [0] orientation,

ii) A cross ply laminate made up of 4layers with [0/90/90/0] orientation.

iii) A quasi-isotropic laminate made up of 8 layers with [0/45/-45/90]s orientation.

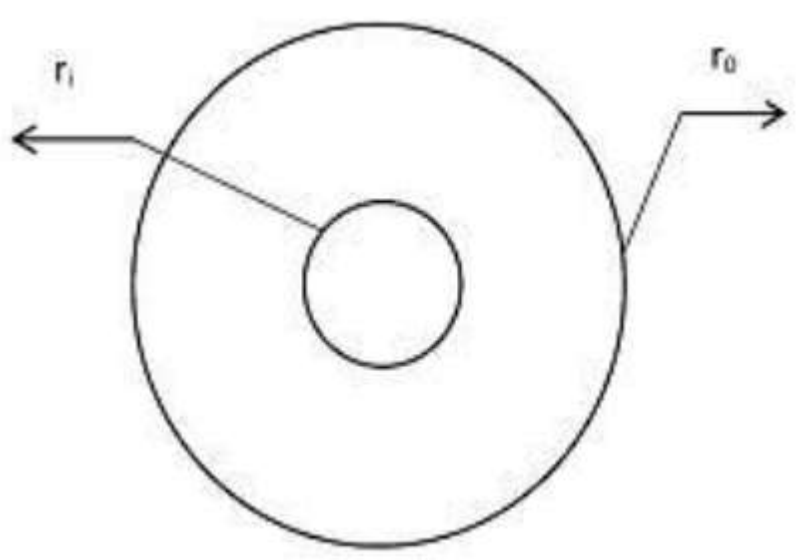

Fig. 1 Annular disc subjected to spinning.

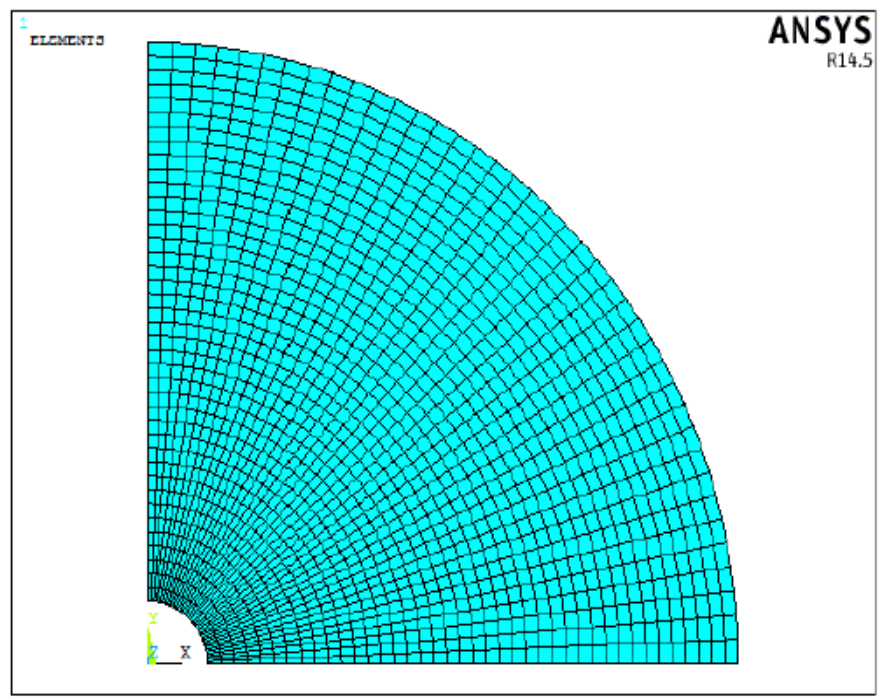

Fig. 2 Finite element model of laminated composite Annular disc subjected to spinning (quarter symmetry).
A Laminated composite annular disc made up of graphite epoxy subjected to spinning.

The same problem as illustrated in fig 1 with the same physical parameters is taken into consideration. The properties of graphite epoxy composite material used in the analysis are $\mathrm{E}_{1}=181 \mathrm{GPa}, \mathrm{E}_{2}=10.3 \mathrm{GPa}, \mathrm{G}_{12}=7.17 \mathrm{GPa}$, $v_{12}=0.28, \quad\left(\sigma_{1}{ }^{\mathrm{T}}\right)_{\mathrm{ult}}=1500 \mathrm{MPa}, \quad\left(\sigma_{1}{ }^{\mathrm{C}}\right) \mathrm{ult}=1500 \mathrm{MPa}, \quad\left(\sigma_{2}{ }^{\mathrm{T}}\right)_{\mathrm{ult}}$ $=40 \mathrm{MPa},\left(\sigma_{2}{ }^{\mathrm{C}}\right)_{\mathrm{ult}}=246 \mathrm{MPa},\left(\tau_{12}\right)_{\mathrm{ult}}=68 \mathrm{MPa}$.

For the present case, the laminated composite annular disc made up of three different stacking sequence is considered i.e with

i) A single layer unidirectional ply with [0] orientation,

ii) A cross ply laminate made up of 4 layers with [0/90/90/0] orientation.

iii) A quasi-isotropic laminate made up of 8 layers with[0/45/-45/90]s orientation.

\section{RESULTS PRESENTATION}

AND

\section{DISCUSSION}

A Laminated composite annular disc made up of glass epoxy subjected to spinning.

The stress distribution results as reported in ref. [1] are in good agreement with the present analysis study. In the immediate vicinity of the hole boundary there is a phenomenon known as free edge effect due to which the stress state in each ply can be three dimensional, stressstrain behaviour in each ply can be non-linear (due to onset and growth of ply failure) and delaminations between plies (onset and growth). This free edge effect is not included in the proposed FE model. A highly refined FE models and a non-linear analysis hopefully can bring out the better results. This is identified as the topic for future research.

There is no accountable analytical solution for the present problem because FEM follows the variational approach and hence the outer circular boundary of the disc remains circular and inner boundary explicitly shows elliptical deformation where-in the analytical solution follows differential function approach which uses the function of variable $\mathrm{x}$ and $\mathrm{y}$ and hence shows outer boundary as well as inner boundary deformation as elliptical.

A sophisticated experimental setup is needed to bridge this gap between FEM and analytical solution. The stress analysis results are graphically post-processed as contour plots at the top, middle, bottom of each layer in the laminate.

For failure analysis, Tsai-wu failure criterion is invoked. The disc is rotated incrementally until the first ply failure occurs.

ANSYS software post-processing capability is exploited to graphically display contour plots of Tsai-Wu failure index which identifies the ply that fails first, the location at which the onset of failure occurs. 
Using progressive failure analysis procedure, the predicted loads at which subsequent plies fail is tabulated in table I. The load at which last ply failure occurs is applied and at that particular load; Tsai-Wu failure index contour plots of all the plies are obtained. An ensemble of these will provide the shape and size of damage.

The results are tabulated here in table I for the laminated composite annular disc made up of glass epoxy for all the three cases i.e unidirectional, cross ply and quasi-isotropic laminate.

Table 1: Ply By Ply Failure Result

Unidirectional Ply

\begin{tabular}{|c|c|c|}
\hline $\begin{array}{c}\text { Sequence of ply } \\
\text { failure }\end{array}$ & $\begin{array}{c}\text { Failed layer } \\
\text { numbers }\end{array}$ & $\begin{array}{c}\text { Failure } \\
\text { loads(rad/s) }\end{array}$ \\
\hline $1^{\text {st }}$ & 1 & 5955.27 \\
\hline
\end{tabular}

\begin{tabular}{|c|c|c|}
\hline \multicolumn{3}{|c|}{ cross plied laminate } \\
\hline $\begin{array}{c}\text { Sequence of ply } \\
\text { failure }\end{array}$ & $\begin{array}{c}\text { Failed layer } \\
\text { numbers }\end{array}$ & $\begin{array}{c}\text { Failure } \\
\text { loads(rad/s) }\end{array}$ \\
\hline $1^{\text {th }}$ & 2,3 & 3357.445 \\
\hline $2^{\text {th }}$ & $1,4$. & 6299.02 \\
\hline
\end{tabular}

Quasi Isotropic Laminate

\begin{tabular}{|c|c|c|}
\hline $\begin{array}{c}\text { Sequence of ply } \\
\text { failure }\end{array}$ & $\begin{array}{c}\text { Failed layer } \\
\text { numbers }\end{array}$ & $\begin{array}{c}\text { Failure } \\
\text { loads(rad/s) }\end{array}$ \\
\hline $1^{\text {st }}$ & 4,5 & 3631.355 \\
\hline $2^{\text {da }}$ & 3,6 & 4897.68 \\
\hline $3^{\text {ta }}$ & 2,7 & 4902.18 \\
\hline $4^{\text {di }}$ & 1,8 & 7493.62 \\
\hline
\end{tabular}

\section{Failure Contours}

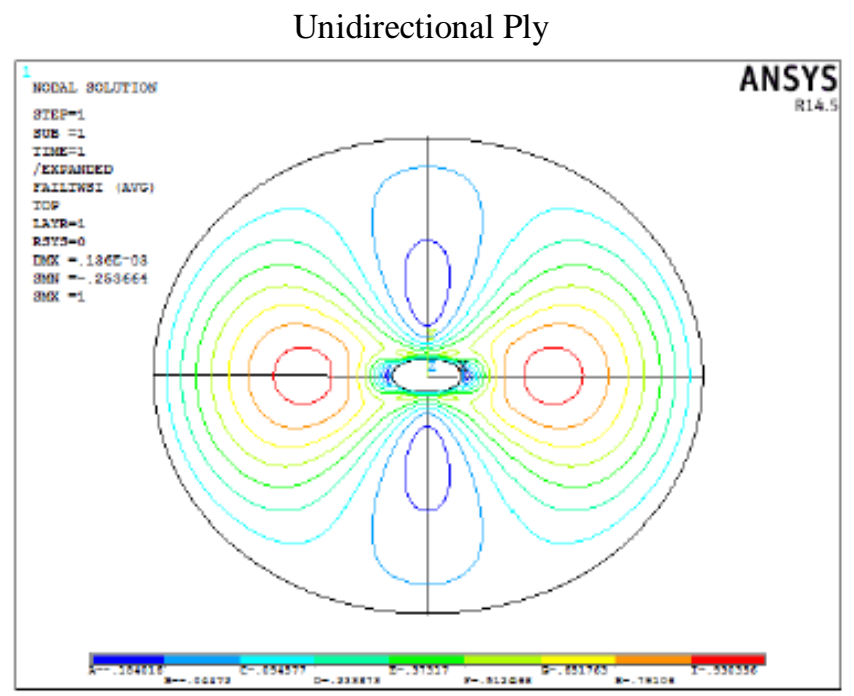

Fig. 3 Tsai-Wu failure index contour plot for layer number 1 at $\omega=5955.27 \mathrm{rad} / \mathrm{s}$

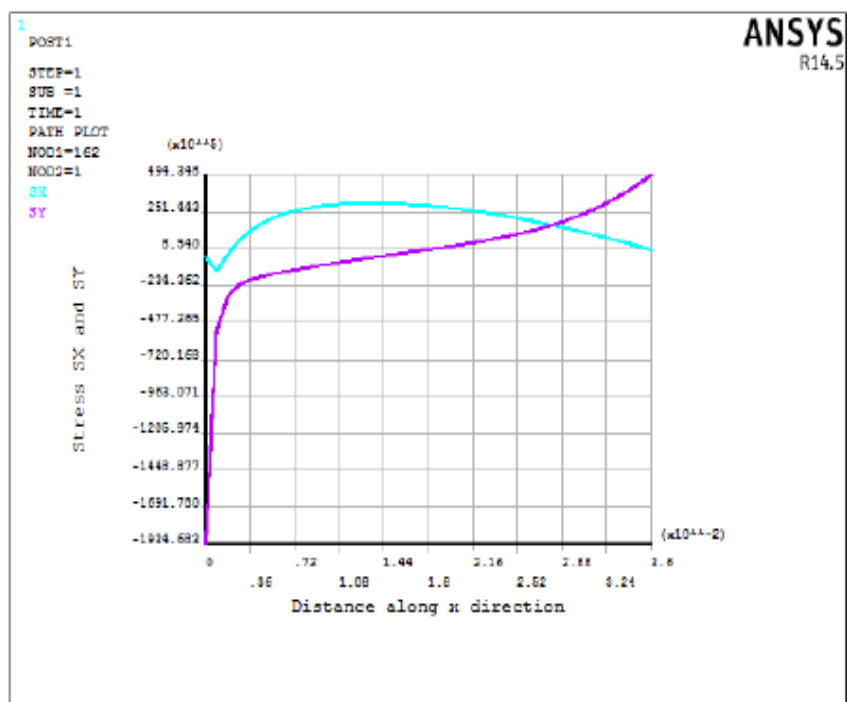

Fig. 4: stress SX and SY along X direction

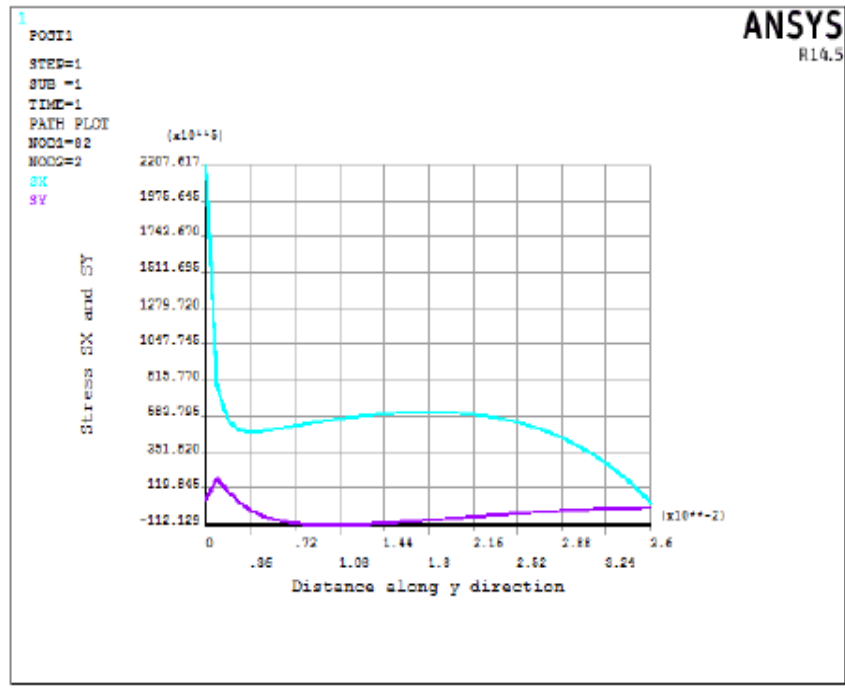

Fig. 5: stress SX and SY along Y direction cross plied laminate

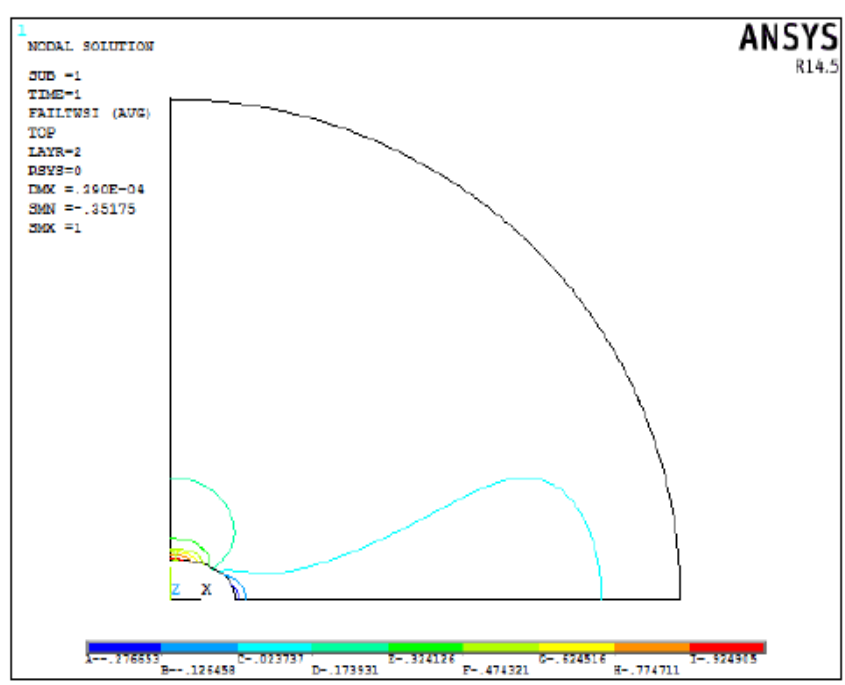

Fig. 6 Tsai-Wu failure index contour plot for layer number 2 at $\omega=3357.445 \mathrm{rad} / \mathrm{s}$ 


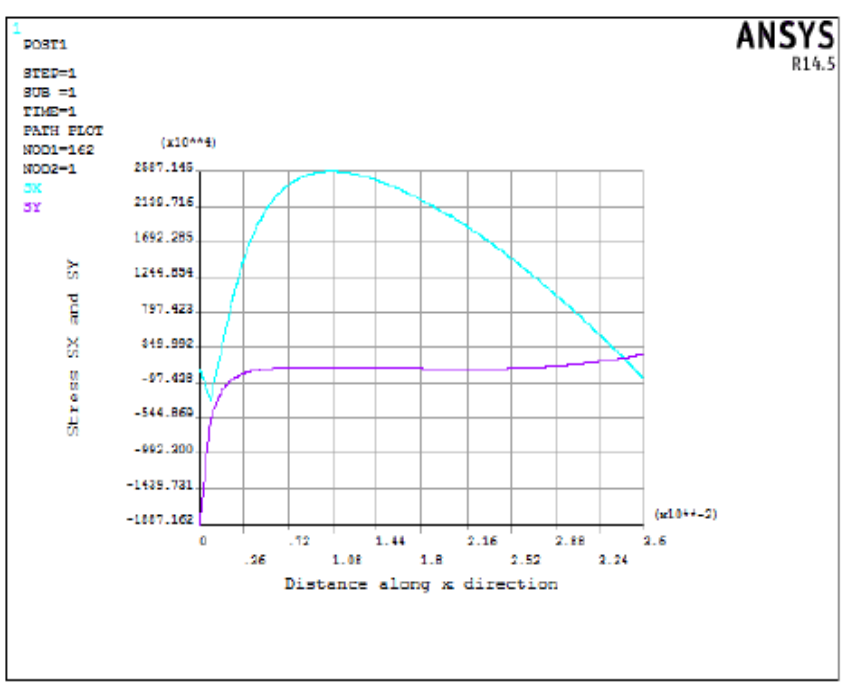

Fig. 7: stress SX and SY along X direction

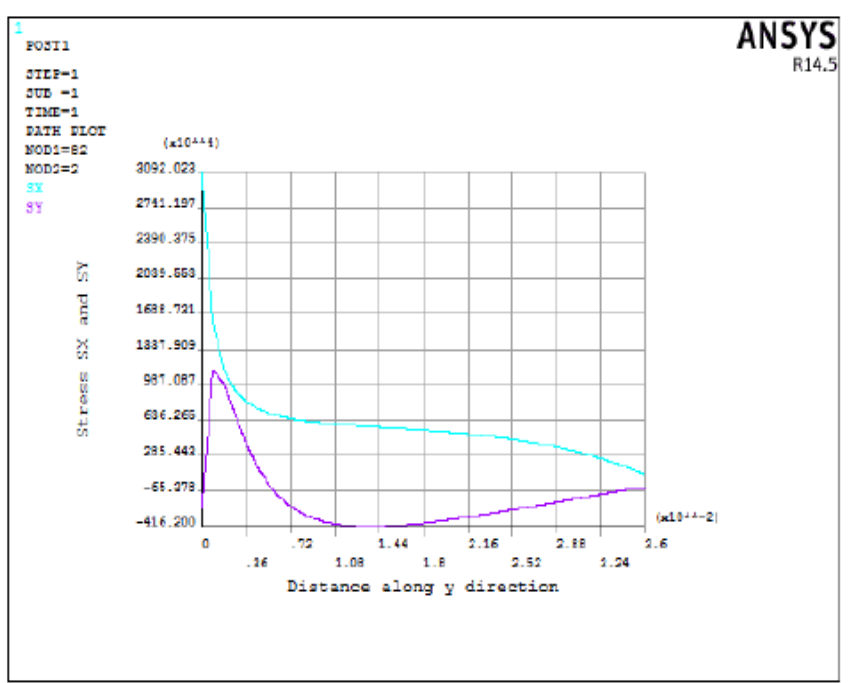

Fig. 8: stress SX and SY along Y direction

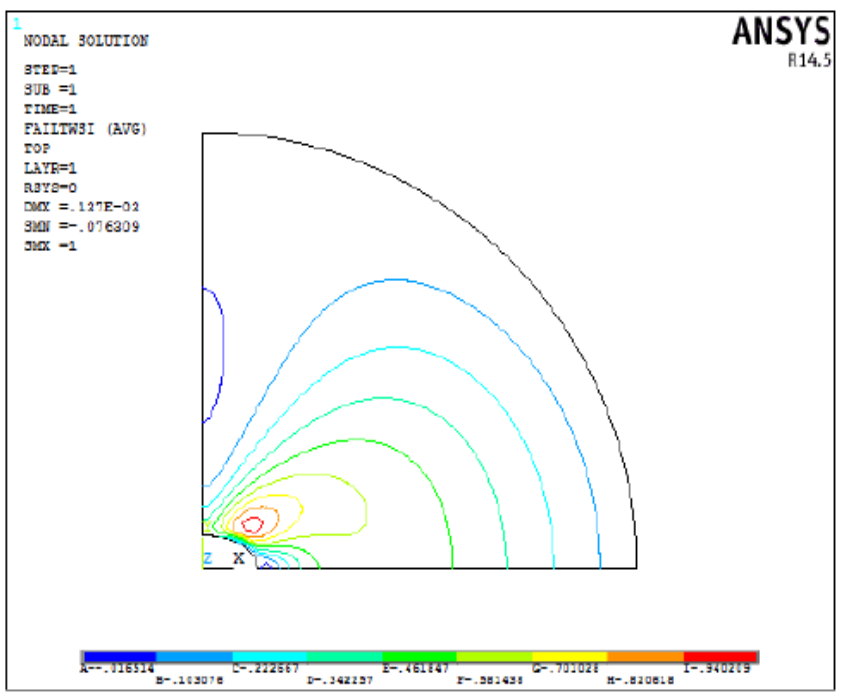

Fig. 9 Tsai-Wu failure index contour plot for layer number 1 at $\omega=6299.02 \mathrm{rad} / \mathrm{s}$

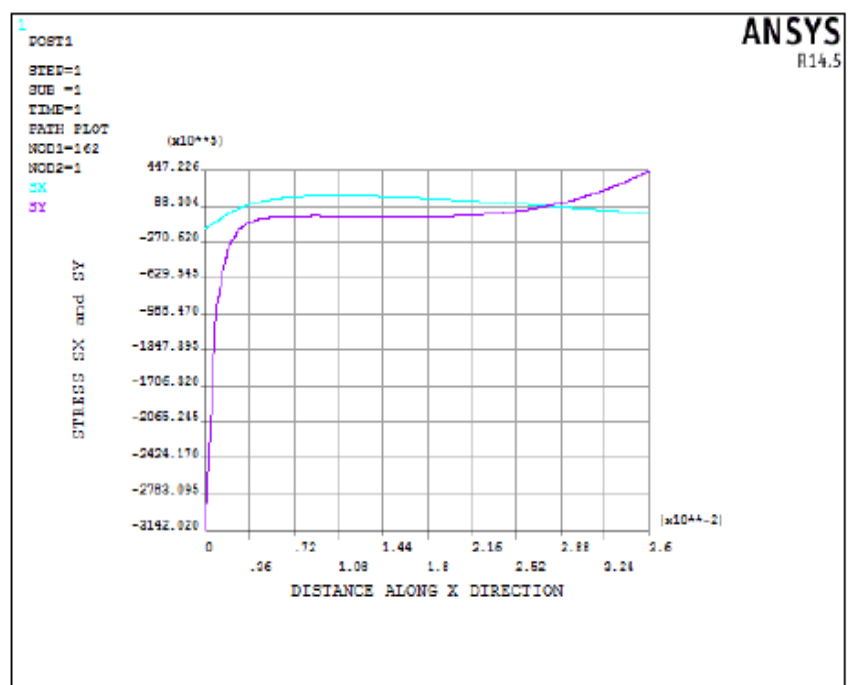

Fig. 10: stress $S X$ and $S Y$ along $X$ direction

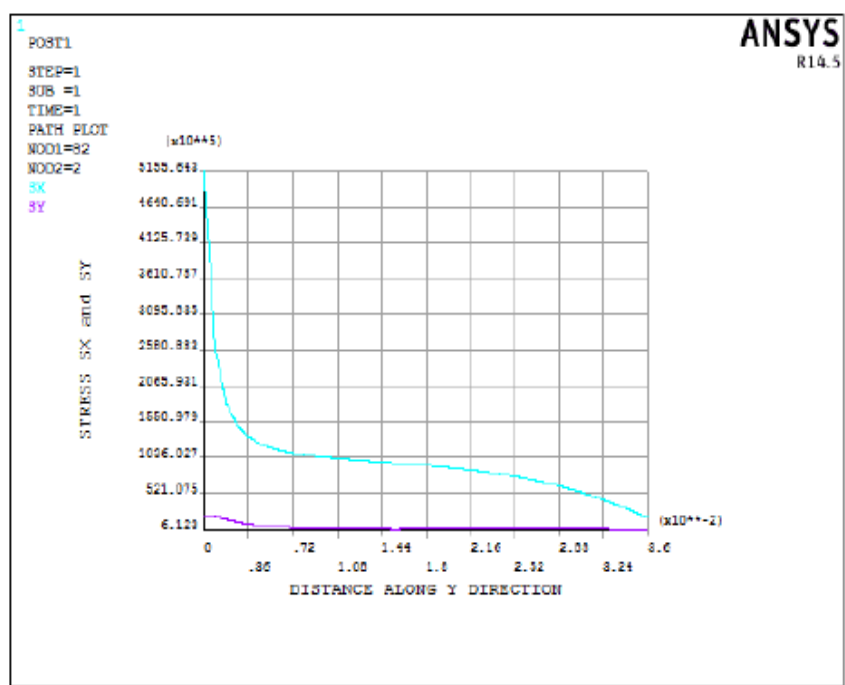

Fig. 11: stress SX and SY along Y direction Quasi Isotropic Laminate

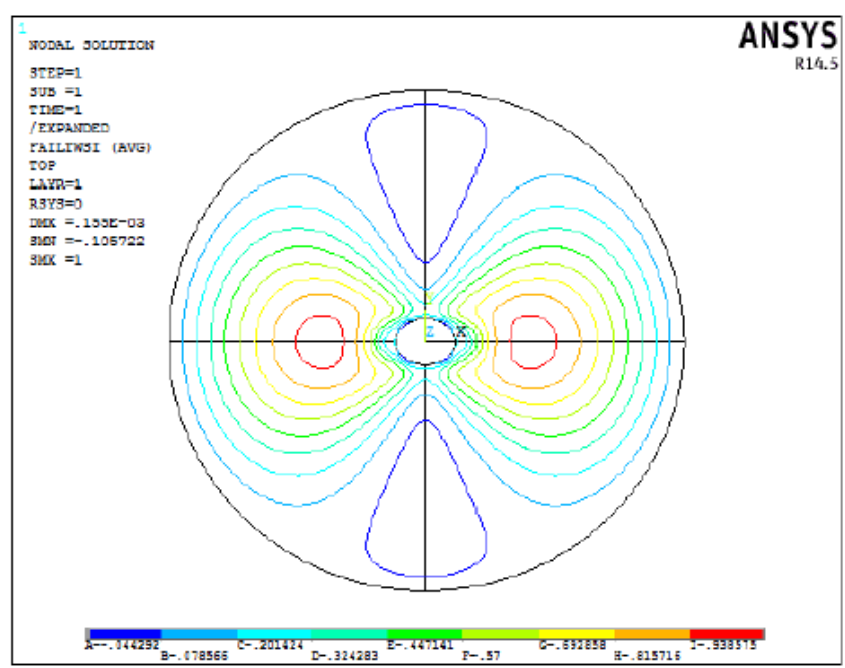

Fig. 12 Tsai-Wu failure index contour plot for layer number 1 at $\omega=7493.62 \mathrm{rad} / \mathrm{s}$ 


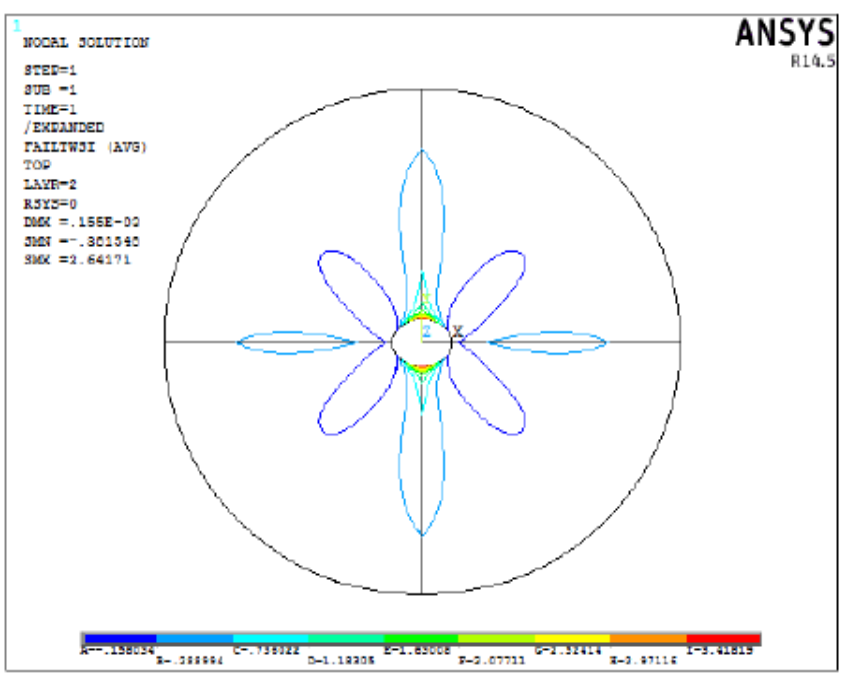

Fig. 13 Tsai-Wu failure index contour plot for layer number 2 at $\omega=7493.62 \mathrm{rad} / \mathrm{s}$

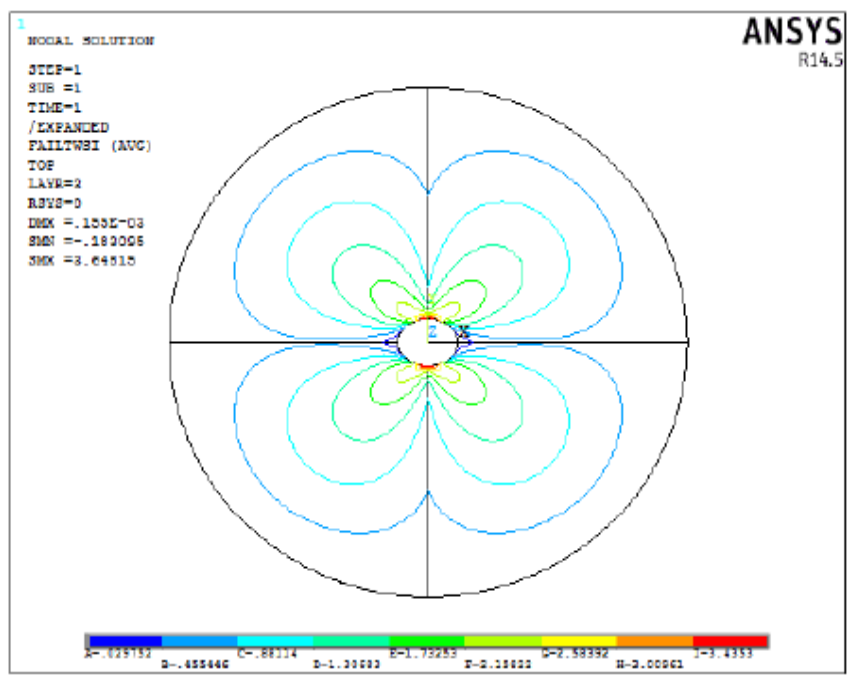

Fig. 14 Tsai-Wu failure index contour plot for layer number 3 at $\omega=7493.62 \mathrm{rad} / \mathrm{s}$

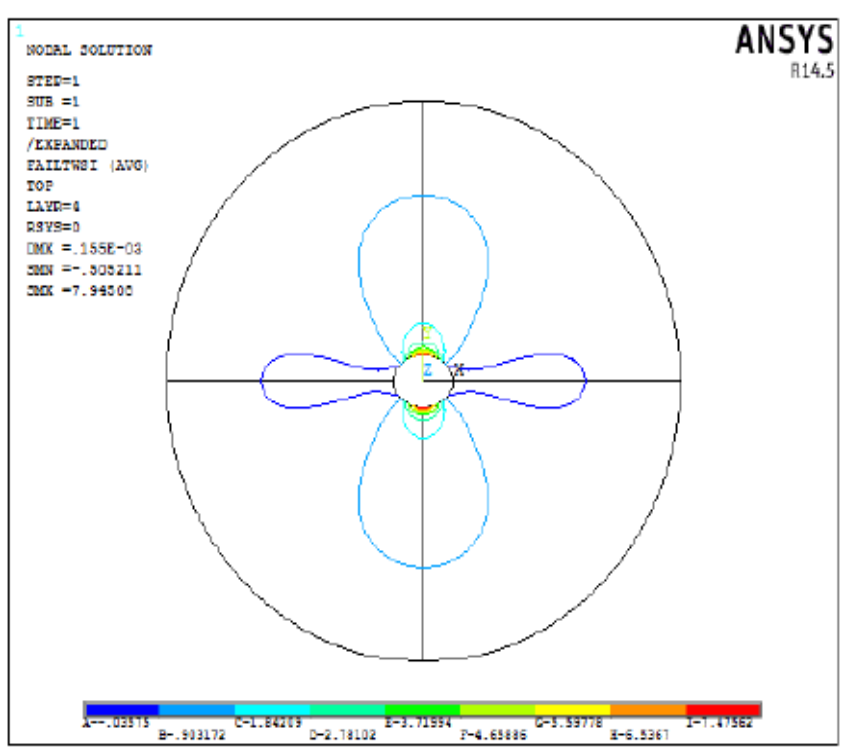

Fig. 15 Tsai-Wu failure index contour plot for layer number 4 at $\omega=7493.62 \mathrm{rad} / \mathrm{s}$
A Laminated composite annular disc made up of graphite epoxy subjected to spinning.

The results are tabulated here in table II for the laminated composite annular disc made up of graphite epoxy for all the three cases i.e unidirectional, cross ply and quasi-isotropic laminate. Finite element modelling using the ANSYS software is the analyst's choice. The FE Model presented above is refined enough to assure engineering accuracy. Using progressive failure analysis procedure, the predicted loads at which subsequent plies fail is tabulated in table I and II. It is gratifying to note that the sequence of ply failure is not obvious. Tsai-wu failure index contour plots at the respective failure loads and at the onset of last ply failure are presented. The maximum Tsai-Wu failure index is 1.0 (red line) and its location is not on the hole boundary. The Tsai$\mathrm{Wu}$ failure index contour plots of all the layers in the laminate are presented in (Figures 3 to 28) along with the stress variation graphs. These figures demonstrate the graphical post processing capability in ANSYS specifically for progressive failure analysis of laminated composite structures.

These figures quantify the onset and growth, nature and extent, shape and size of damage ply by ply. However, the mode of failure is not identifiable. An ensemble of all these figures is desirable to quantify the shape and size of damage zone in the laminate and its location in the plate. This information is vital to verify the prediction methodology proposed in this study.

Verification demands experimental data. State of the art NDT namely computerised ultrasonic C-scan can provide this data.

However, current graphical post-processing in ANSYS cannot provide the above ensemble. These are identified as topics for research and development in this area.

Table 2: Ply by ply failure result

\begin{tabular}{|c|c|c|}
\hline \multicolumn{3}{|c|}{ Unidirectional Ply } \\
\hline $\begin{array}{c}\text { Sequence of ply } \\
\text { failure }\end{array}$ & $\begin{array}{c}\text { Failed layer } \\
\text { numbers }\end{array}$ & $\begin{array}{c}\text { Failure } \\
\text { loads(rad/s) }\end{array}$ \\
\hline $1^{\text {st }}$ & 1 & 7001.23 \\
\hline
\end{tabular}

\begin{tabular}{|c|c|c|}
\hline \multicolumn{3}{|c|}{ Cross Plied Laminate } \\
\hline $\begin{array}{c}\text { Sequence of ply } \\
\text { failure }\end{array}$ & $\begin{array}{c}\text { Failed layer } \\
\text { numbers }\end{array}$ & $\begin{array}{c}\text { Failure } \\
\text { loads(rad/s) }\end{array}$ \\
\hline $1^{\text {st }}$ & 2.3 & 5625.569 \\
\hline $2^{\text {sd }}$ & $1,4$. & 5715.98 \\
\hline
\end{tabular}




\begin{tabular}{|c|c|c|}
\hline \multicolumn{3}{|c|}{ Quasi Isotropic Laminate } \\
\hline $\begin{array}{c}\text { Sequence of ply } \\
\text { failure }\end{array}$ & $\begin{array}{c}\text { Failed layer } \\
\text { numbers }\end{array}$ & $\begin{array}{c}\text { Failure } \\
\text { loads(rad/s) }\end{array}$ \\
\hline $1^{\text {st }}$ & 4.5 & 7055.89 \\
\hline $2^{\text {sd }}$ & 2,7 & 7904.65 \\
\hline $3^{\text {th }}$ & 3,6 & 7907.86 \\
\hline $4^{\text {th }}$ & 1.8 & 10205.09 \\
\hline
\end{tabular}

\section{Unidirectional Ply}

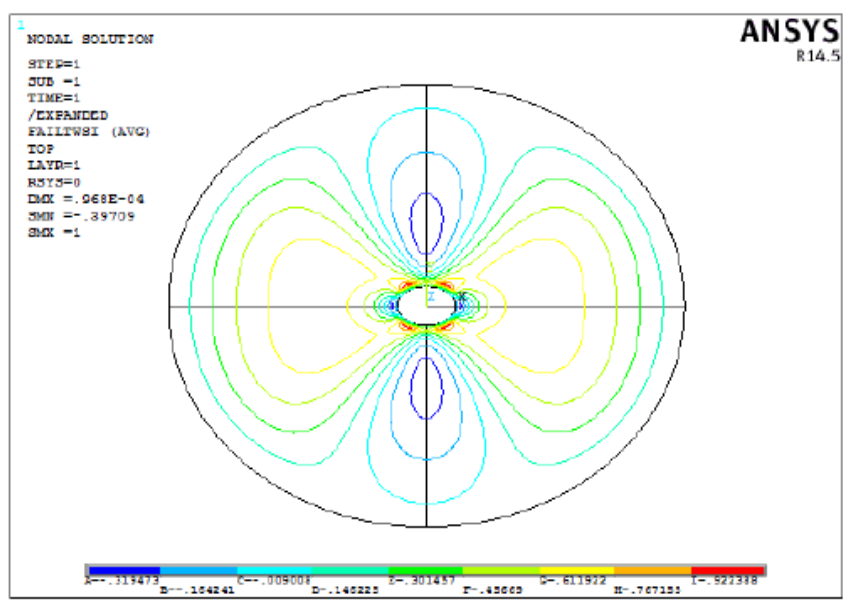

Fig. 16 Tsai-Wu failure index contour plot for layer number 1 at $\omega=7001.23 \mathrm{rad} / \mathrm{s}$

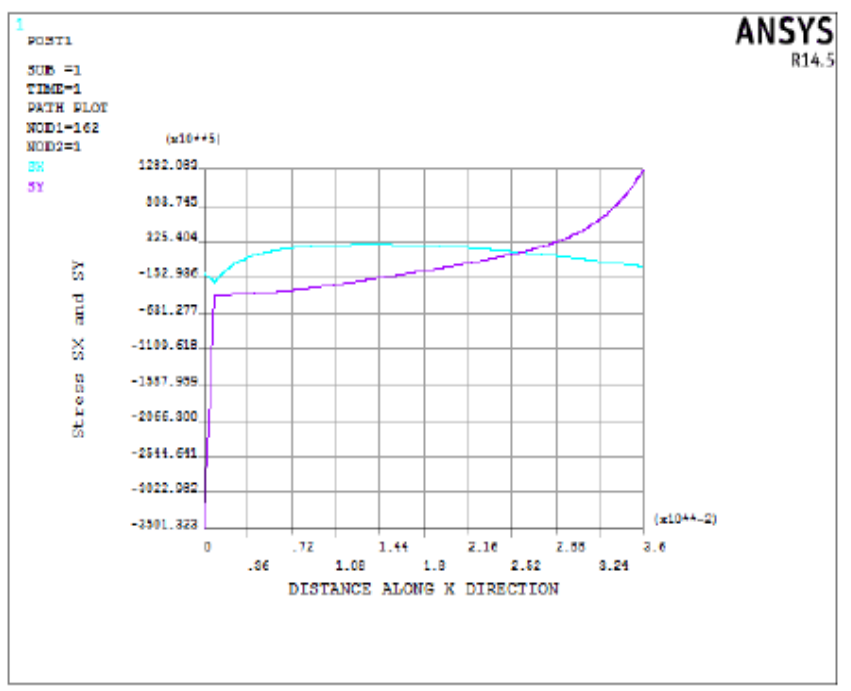

Fig. 17: stress SX and SY along X direction

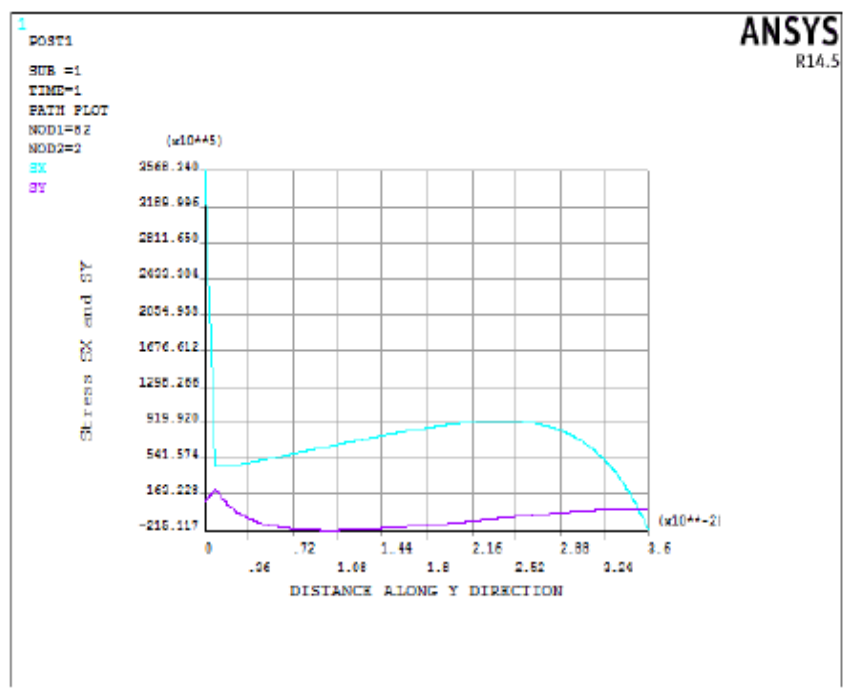

Fig. 18: stress SX and SY along Y direction

\section{Cross Plied Laminate}

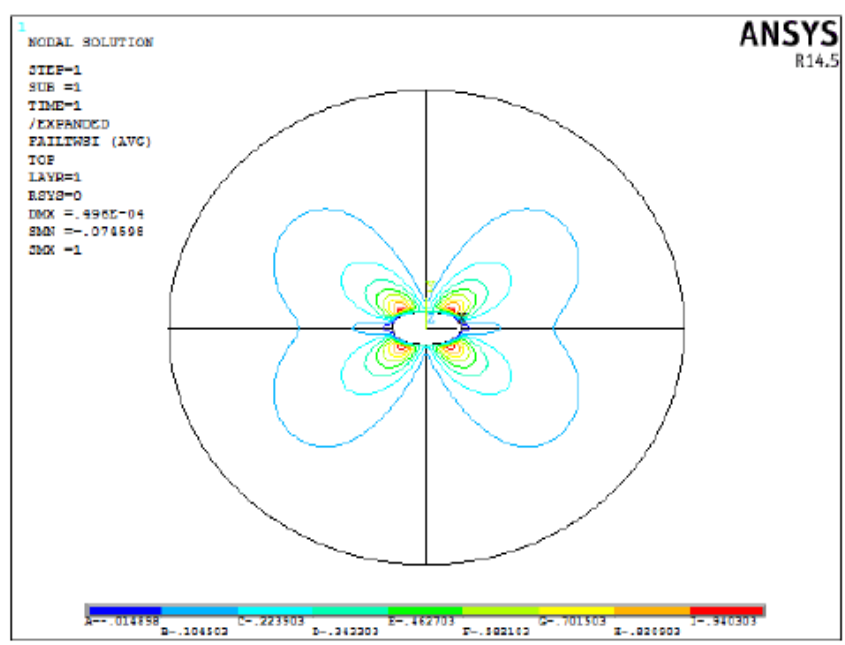

Fig. 19 Tsai-Wu failure index contour plot for layer number 1 at $\omega=5715.98 \mathrm{rad} / \mathrm{s}$

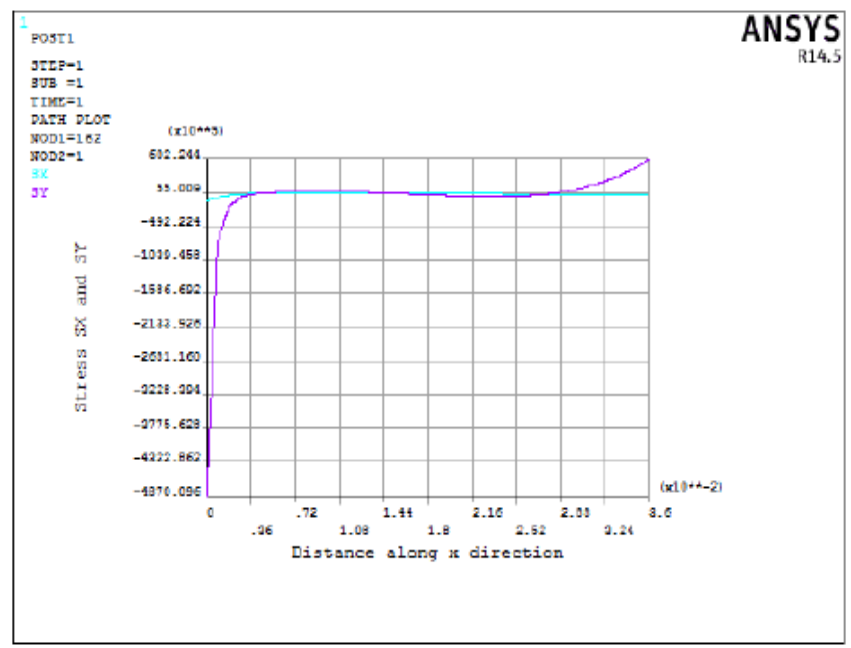

Fig. 20: stress SX and SY along $X$ direction 


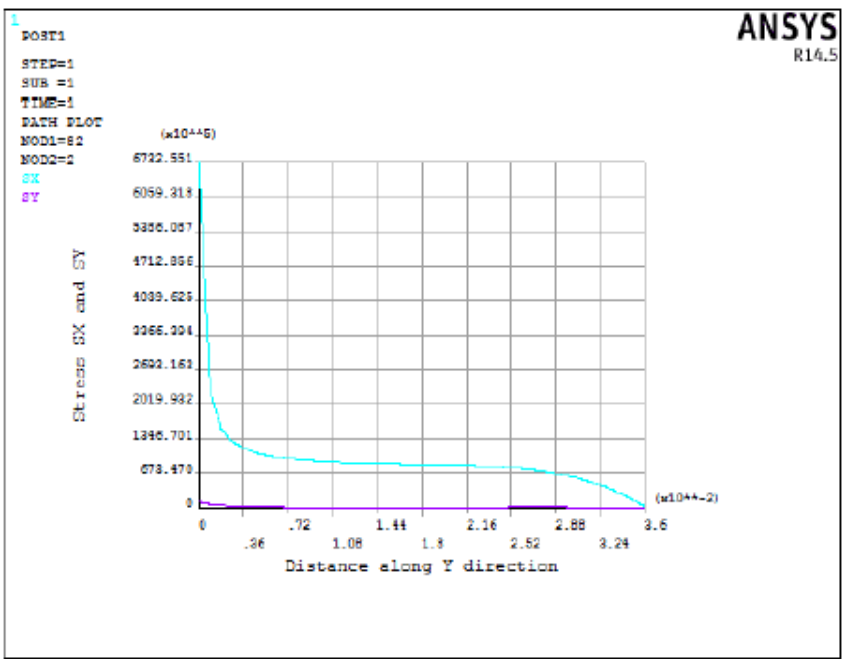

Fig. 21: stress SX and SY along Y direction

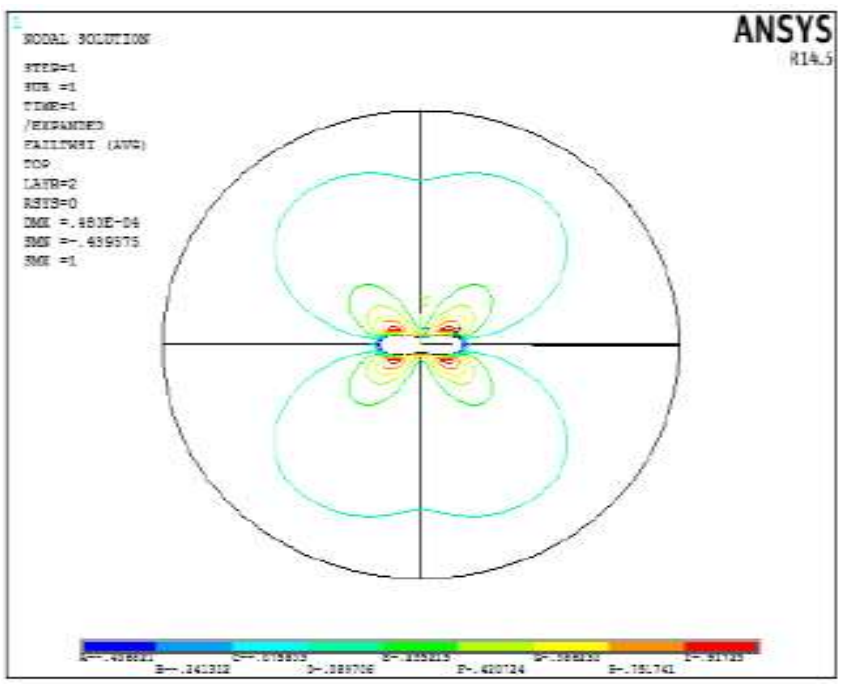

Fig. 22 Tsai-Wu failure index contour plot for layer number 2 at $\omega=5625.569 \mathrm{rad} / \mathrm{s}$

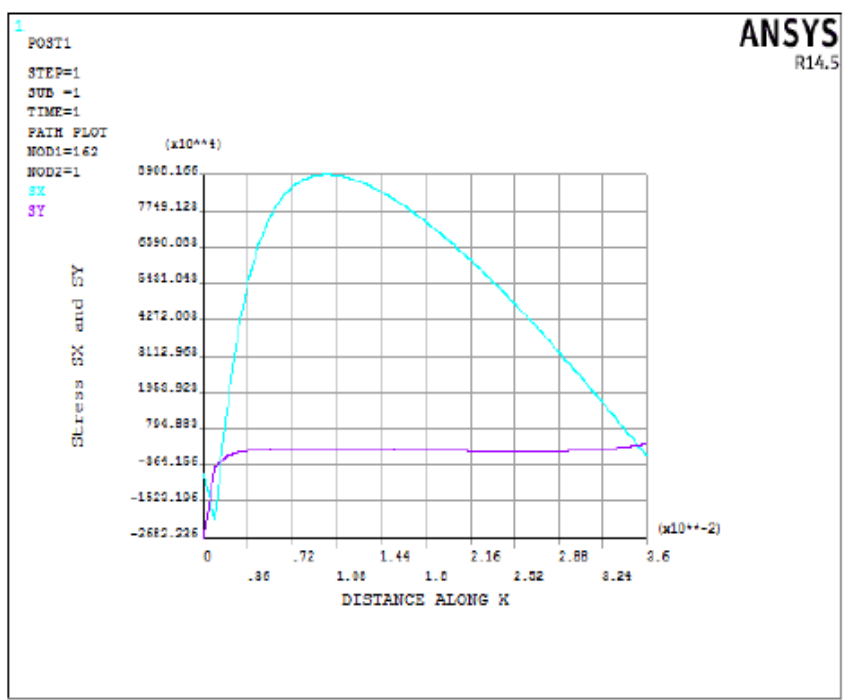

Fig. 23: stress SX and SY along X direction

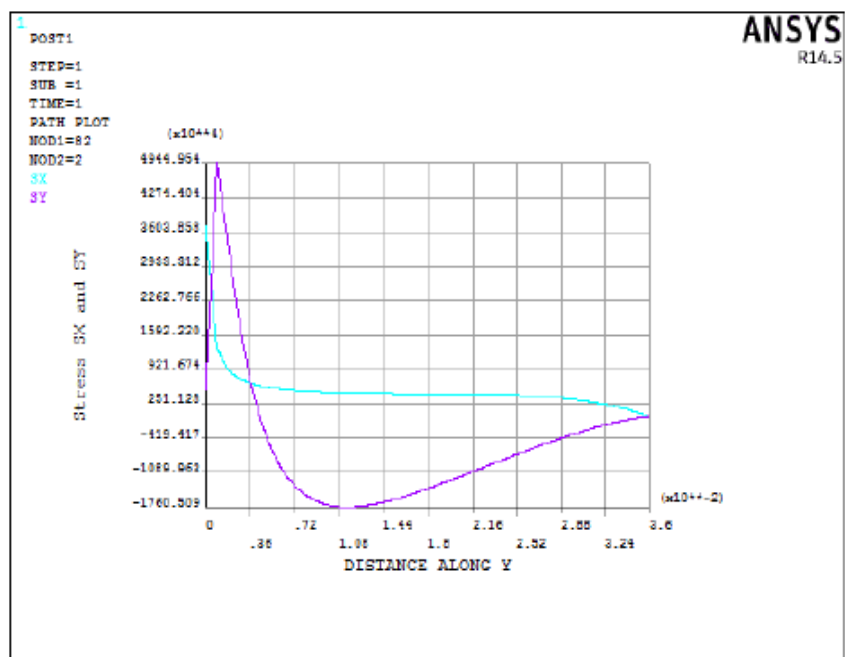

Fig. 24: stress SX and SY along Y direction Quasi-istropic laminate

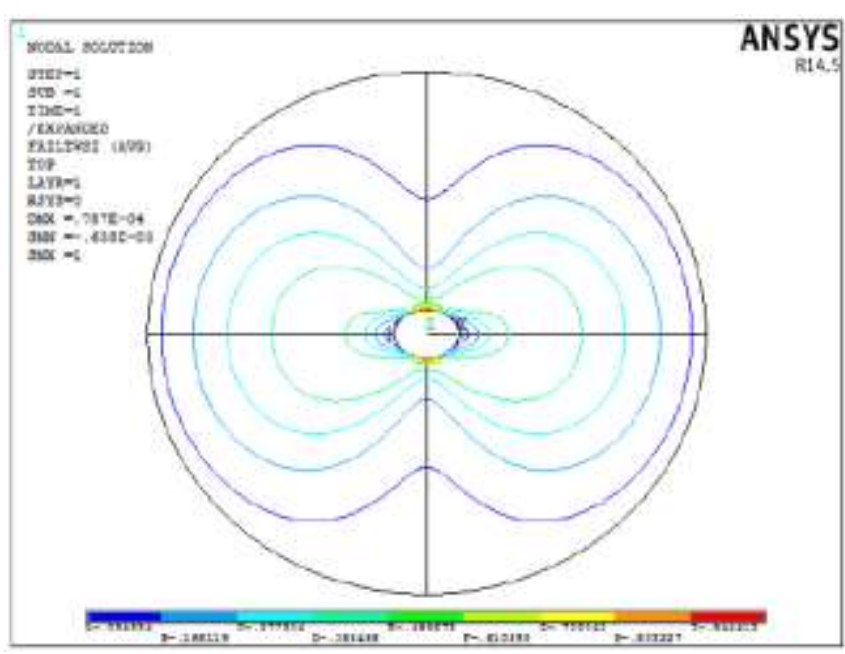

Fig. 25 Tsai-Wu failure index contour plot for layer number 1 at $\omega=10205.09 \mathrm{rad} / \mathrm{s}$

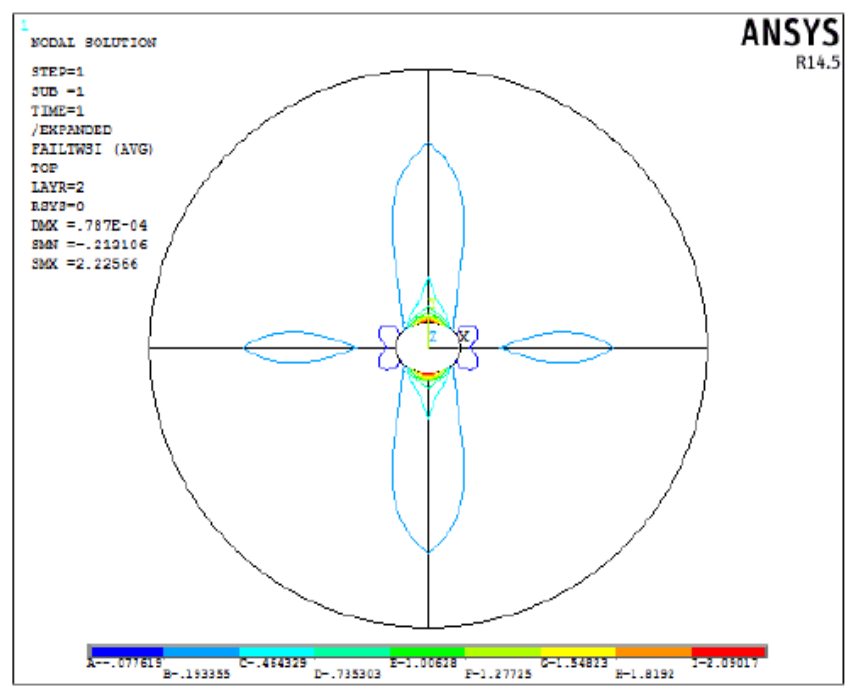

Fig. 26 Tsai-Wu failure index contour plot for layer number 2 at $\omega=10205.09 \mathrm{rad} / \mathrm{s}$ 


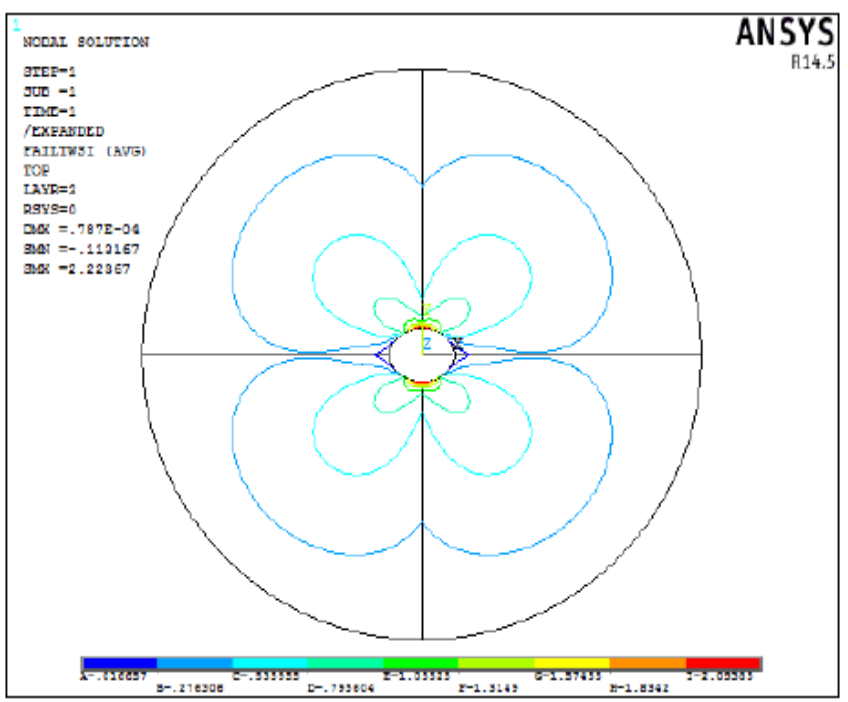

Fig. 27 Tsai-Wu failure index contour plot for layer number 3 at $\omega=10205.09 \mathrm{rad} / \mathrm{s}$

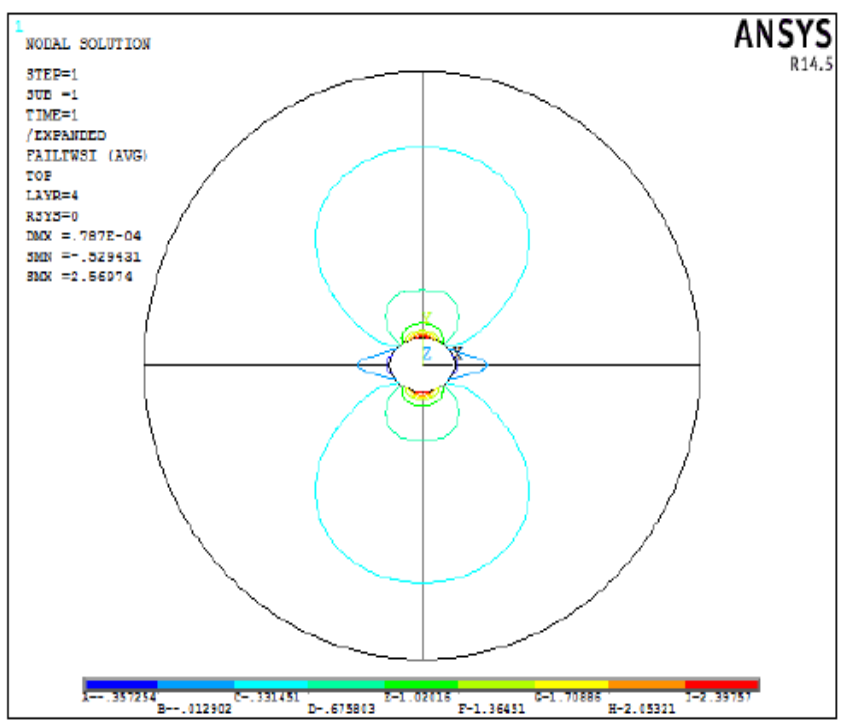

Fig. 28 Tsai-Wu failure index contour plot for layer number 4 at $\omega=10205.09 \mathrm{rad} / \mathrm{s}$

\section{CONCLUSION}

Ultimate strength prediction of a laminated composite structure is an order of magnitude more complicated than stress analysis.

In this study the Tsai-wu failure criterion along with experimentally measured lamina stiffness and strength properties and the concept of strength ratio are used to predict failure loads (first ply failure to last ply failure).

However, the last ply failure load is not the ultimate strength.

The powerful post processing capability in ANSYS software is exploited to graphically present contour plots of ply by ply stresses and Tsai-wu failure index.
Based on the present study it can be concluded that the FEM in general and commercial FEA software ANSYS in particular is a unified approach for stress analysis and for progressive failure analysis of laminated composite structures.

In this study correlation of numerical results of FEA was restricted to limited experimental results reported for the problems on hand. However there is a real need for sophisticated experimental investigations to verify all the results presented here. This is identified as future work. Finally, there is a need for fully instrumented spin tests: first to validate the numerical solutions and second to demonstrate the usefulness of such solutions in the calculation of failure speeds.

\section{REFERENCES}

[1]. Lakshminarayana H.V., "Finite element analysis of rotating laminated composite annular discs" composites. volume 17. no 1 . January 1986.

[2]. Belingardi, G., Gent\& G. and Gola, M. 'A study of the stress distribution in rotating orthotropic discs" Composites 10 No 2 (April 1979) pp 77-80.

[3]. Genta, G. and Gola, NL 'The stress distribution in orthotropic rotating disks' ASME J of Applied Mechanics 48 (September 1981) pp 559-562.

[4]. Y.W. Kim and C.S. Hong; Progressive Failure Model for the Analysis of Laminated Composites based on Finite Element Approach; Journal of Reinforced Plastics and Composites 1992, pp 11 to 1078. 